\title{
Dominasi Kultural Figur Bunda Maria Dalam Ritual Semana Santa Pada Masyarakat Larantuka, Flores Timur
}

\author{
Abima Narasatriangga ${ }^{*}$, Purwadi ${ }^{2}$, I Nyoman Dhana ${ }^{3}$ \\ ${ }^{[123]}$ Prodi Antropologi Fakultas Ilmu Budaya Unud \\ ${ }^{1}$ [narasatriangga@gmail.com] ${ }^{2}$ [kuyahambu@yahoo.com] \\ [nyomandhana@ymail.com] \\ *Corresponding Author
}

\begin{abstract}
Mary's figure is so exclusive to the people of Larantuka City which appear in the Semana Santa ritual. In addition, in Lera Wulan Tanah Ekan's lamaholot ethnic pre-Catholic religious system which views female figures as representations of the universe, it brings forth an allegation to the author that there is a correlation with the cultural dominance of The Virgin Mary figure. This research analyzes Semana Santa's ritual phenomenon as the main indicator of Larantuka society's exclusive appreciation and perception background toward The Virgin Mary and try to seek, Larantuka people as Lamaholot ethnic have a cultural value called lewotana covering all the values they embrace and implement, including the value in their religious system. In order understanding from Larantuka society's point of view as the culprit. This research uses Schultz and Husserl phenomenology theory. Before the arrival of the Catholic culture to understand by finding the background about the phenomenon of change of cultural values of the lewotana developing into the cultural value of Catholic, researcher used the theory of phenomenology. In addition, Geertz's interpretive and ethnoscience approach as a supporting theory. The research method that will be used is qualitative method. This is because qualitative methods are more representative and relevant for observations and detailed interviews. The final outcome of this study answers two problems, the first one revealing how the procession of Semana santa ritual which implicitly contain the value of feminism that appears on activity and ritual attributes. The value is represented through the figure of The Virgin Mary. It also describes the history of Semana santa development associated with the acculturation process of Lamaholot culture with Catholic culture. The second is the cultural dominance of The Virgin Mary figure which motivated by the characteristic and cultural value of Lamaholot (pre-Catholic) which is feminist. The phenomenon of the cultural system religion of Larantuka society alteration from Lera Wulan Tanah Ekan and Lewotana into Catholic culture only occurs at the level of social behavior and artifacts, the idea of the value of the sacred women figure who is considered as a representation of the universe still exist in the cognitive nature of Larantuka society with the figure of The Virgin Mary as a substitution process media of feminist value along with symbol as "place" meaning to the admiration and respect to woman figure, especially mother.
\end{abstract}

Key Words: Ritual, The Virgin Mary, Semana Santa

\begin{abstract}
Abstrak
Figur Bunda Maria begitu eksklusif bagi masyarakat Kota Larantuka yang nampak dalam ritual Semana Santa. Sistem religi pra-Katolik etnis lamaholot yaitu Lera Wulan Tanah Ekan yang memandang figur perempuan sebagai representasi alam semesta, memiliki andil dalam terbentuknya dominasi kultural figur Bunda Maria tersebut. Penelitian ini mengangkat dua permasalahan, yaitu prosesi ritual Semana Santa sebagai indikator utama dominasi Bunda Maria dan bagaimana bentuk dominasi kultural figur Bunda Maria pada masyarakat Larantuka. Penelitian ini menggunakan teori fenomenologi Schultz dan Husserl. Sebelum datangnya budaya Katolik, masyarakat Larantuka sebagai etnis Lamaholot memiliki nilai budaya dengan
\end{abstract}


sebutan lewotana yang mencakup segala nilai-nilai yang mereka anut dan implementasikan, termasuk nilai dalam sistem religi mereka. Dalam rangka memahami dengan menemukan latarbelakang mengenai fenomena perubahan nilai budaya lewotana tersebut menjadi nilai budaya Katolik peneliti menggunakan teori fenomenologi. Selain itu, interpretatif Geertz dan pendekatan etnosains sebagai teori pendukung. Metode penelitian yang akan digunakan adalah metode kualitatif. Hal ini dikarenakan metode kualitatif lebih representatif dan relevan dengan melakukan observasi serta wawancara mendetail. Hasil akhir penelitian ini menjawab dua permasalahan, yaitu pertama mengungkapkan bagaimana jalannya prosesi ritual Semana santa yang secara tersirat mengandung nilai feminisme yang nampak pada aktivitas serta atribut ritual. Nilai tersebut terepresentasi melalui figur Bunda Maria. Menjabarkan sejarah perkembangan Semana santa yang berkaitan dengan proses akulturasi budaya Lamaholot dengan budaya Katolik. Kedua yaitu bentuk-bentuk dominasi kultural figur Bunda Maria yang dilatarbelakangi oleh karakteristik dan nilai budaya Lamaholot (pra-Katolik) yang feminis. Fenomena perubuhan sistem budaya-religi masyarakat Larantuka dari Lera Wulan Tanah Ekan dan Lewotana menjadi budaya Katolik hanyalah terjadi pada tataran perilaku sosial dan artefak, ide mengenai nilai akan sakralnya sosok wanita yang dianggap sebagai representasi alam semesta tetap eksis dalam alam kognitif masyarakat Larantuka dengan figur Bunda Maria sebagai media proses substitusi nilai feminis tersebut serta simbol sebagai "tempat" makna atas kekaguman dan penghormatan terhadap sosok wanita, khususnya ibu.

Kata Kunci: Ritual, Bunda Maria, Semana Santa

\section{Latar Belakang}

Sistem religi dalam kehidupan masyarakat merupakan satu unsur dalam kebudayaan yang bersifat universal. Walaupun dengan karakteristik yang berbeda, dalam masyarakat di belahan dunia manapun mulai dari masyarakat tradisional, modern hingga postmodern memiliki sistem religi. Stephen K. Sanderson (2011:517) mengatakan bahwa sistem religi adalah suatu ciri kehidupan sosial manusia yang universal dalam arti bahwa semua masyarakat mempunyai cara-cara berpikir dan polapola perilaku yang memenuhi syarat untuk disebut "agama" (religious). Banyak dari apa yang berjudul sistem religi termasuk dalam superstruktur: sistem religi terdiri dari tipe-tipe simbol, citra, kepercayaan, dan nilai-nilai spesifik dengan mana makhluk manusia menginterpretasikan eksistensi mereka.

Masyarakat dalam mengimplementasikan nilai-nilai spiritual yang ada pada sistem religinya, melaksanakan sebuah tindakan kolektif. Toni Rudyansjah (2015:94) dalam tulisannya menyatakan Emile Durkheim berpendapat bahwa fenomena religius diatur secara alami di dalam dua kategori mendasar: kepercayaan dan ritual. Durkheim lebih lanjut berargumen bahwa setiap kepercayaan religius selalu mempersyaratkan adanya sebuah klasifikasi akan berbagai hal, baik yang bersifat riil maupun gagasan yang manusia pikirkan, dan membaginya ke dalam dua katagori yang berlawanan, yaitu katagori sakral dan profan. Dengan demikian kepercayaan religius merupakan satu representasi yang mengekspresikan hakikat dari berbagai hal yang sakral. Adapun ritual merupakan suatu modus perilaku yang seharusnya dilakukan ketika berhadapan dengan objek yang sakral itu.

Kota Larantuka Kabupaten Flores Timur, Nusa Tenggara Timur (NTT), terdapat sebuah ritual keagamaan yang disebut Semana Santa. Ritual Semana Santa merupakan ritual yang diselenggarkan dalam rangka merayakan pekan hari raya Paskah umat Katolik yang rutin diselenggarakan setiap tahun. Semana Santa merupakan salah satu ritual yang diwariskan oleh para imam 
Katolik Portugis Ordo Dominikan pada masa kolonial dengan mengadopsi unsurunsur budaya lokal. Dalam prosesi ritual Semana Santa tersebut, secara sosiokultural sosok Bunda Maria begitu dominan dengan indikasi apresiasi, persepsi, dan devosi masyarakat terhadapnya sungguh istimewa dan eksklusif.

Bentuk domonasi figur Bunda Maria dalam prosesi Semana Santa secara eksplisit nampak pada beberapa subritualnya. Seperti pada Rabu Trewa, Kamis Putih, Jumat Agung, dan Minggu Alleluya. Serta tema Semana Santa yang selalu merepresentasikan kesedihan dan ketabahan Bunda Maria. Sedangkan bentuk domonasi di luar prosesi nampak pada penobatan Bunda Maria oleh Raja Larantuka sebagai penguasa Larantuka, patung-patung Bunda Maria yang mengisi sudut-sudut kota, menjadi ikon dan simbol kota dan Paroki, serta menjadi panutan atau role model bagi masayarakat Larantuka.

Rangkaian prosesi ritual Semata Santa terdiri dari Minggu Palma, Rabu Trewa, Kamis Putih, Jumat Agung atau Sesta Vera, Sabtu Santo, dan Minggu Paskah. Ritual Semata Santa adalah konstalasi dari ritual-ritual yang berlangsung selama sepekan, jadi pada ritual Semata Santa terdapat sub-sub ritual yang saling terintegrasi. Jumat Agung yang disebut juga Jumat Besar dan Sesta Vera adalah hari yang paling penting sebagai inti dari rangkaian ritual Semana Santa.

Puncak prosesi Semana Santa adalah subritual Jalan Salib pada Jumat Agung. Berbeda dengan ritual dengan jalan salib di berbagai komunitas Katolik di dunia, Semana Santa bukan sekedar dalam rangka mengenang sengsara dan penyaliban Yesus belaka, melainkan mengenang derita dan kesedihan Bunda Maria sebagai ibu dari Yesus yang menyaksikan sekaligus mengiringi kesengsaraan yang Yesus alami dalam kisah penyaliban-Nya.

Selain budaya katolik yang memang sangat menghormati Bunda Maria, ideologi mengenai figur perempuan sebagai representasi alam semesta dalam nilai budaya etnis Lamaholot (penghuni awal Larntuka) yang dikenal dengan sebutan lewonata menjadi temuan penting dalam mengkaji fenomena dominasi kultural figur Bunda Maria. Sistem religi awal masyarakat Larantuka Lera Wulan Tana Ekan juga memiliki andil. Sistem religi yang memercayai adanya roh dan mahkluk gaib yang memengaruhi kehidupan manusia. Salah satunya adalah Tonu Wujo yang dipercaya sebagai dewi kesuburan. Etnis Lamaholot sangat mengagumi dan menghormati Tonu Wujo sebagai dewi kesuburan. Hal inilah mengapa hadirnya patung Tuan Ma (Bunda Maria) dulu dianggap sebagai kehadiran Tonu Wujo dalam bentuk lain.

Data yang didapat selama melaksanakan penelitian tersebut melahirkan dugaan bagi penulis bahwa terdapat korelasi antara sistem religi dan nilai budaya etnis Lamaholot (praKatolik) dengan dominasi kultural figur Bunda Maria di Larantuka, khusunya yang nampak pada ritual Semana Santa. Fenomena dominasi kultural figur Bunda Maria tersebut merupakan satu hal yang yang sangat menarik untuk di analisa dan dipahami.

\section{Pokok Permasalahan}

Berdasarkan latar belakang yang telah dipaparkan di atas, maka rumusan masalah dari penelitian ini adalah:

a. Bagaimana prosesi ritual Semana Santa pada masayarakat Kota Larantuka?

b. Bagaimana dominasi figur Bunda dalam ritual Semana Santa pada masyarakat Larantuka? 


\section{Tujuan Penelitian}

Tujuan dari penelitian ini adalah mengetahui jalannya prosesi Semana Santa serta memahami kaitannya dengan dominasi Bunda Maria dalam prosesi ritual pada masyarakat Larantuka tersebut. Serta mengetahui bentuk dan latarbelakang dominasi kultural figur Bunda Maria pada masyarakat Larantuka, khususnya dalam ritual Semana Santa.

\section{Metode Penelitian}

Penelitian ini menggunakan metode kualitatif. Dalam aplikasinya, metode kualitatif akan digunakan oleh peneliti untuk memperoleh deskripsi kebudayaan secara lebih mendalam (thick description) mengenai kebudayaan masyarakat Larantuka dan etnis Lamaholot. Jenis data dalam penelitian ini adalah data kualitatif yang sifatnya deskriptif bersumber dari data primer dan sekunder hasil dari wawancara dan observasi partisipasi di lapangan serta studi pustaka.

\section{Hasil dan Pembahasan}

\subsection{Prosesi Ritual Semana Santa Pada Masyarakat Kota Larantuka}

Ritual Semana Santa

diselenggarakan oleh masayarakat Larantuka yang secara eksplisit dilatarbelakangi oleh emosi keagamaan khususnya umat Katolik Larantuka. Ritual yang berlangsung setiap satu tahun sekali ini, secara kronologis memiliki rangkaian yang panjang dan memiliki sub-sub ritual pendukung tarhadap ritual utamanya. Jika diakumulasi dari segi durasi pelaksanaan ritual pendukung juga ritual utamanya, Semana Santa berlangsung satu bulan lebih. Ritual utama Semana Santa berlangsung selama seminggu yaitu dimulai pada Minggu Palma sampai dengan Minggu Paskah. Sedangkang ritual pendukung sebelum Minggu Palma, terdapat ritual Mengaji
Semana. Ritual Semana Santa merupakan ritual yang diwariskan para misionaris Portugis dengan mengadopsi kearifan lokal budaya lokal.

Minggu Palma adalah momen awal dari rangkain ritual Semana Santa. Minggu Palma atau Dominggu Ramu yang oleh masyarakat lokal kerap disebut juga dengan Minggu Daun-Daun tidak saja diwarnai dengan perayaan Liturgis tetapi juga perayaan devosional. Confreria bersama umat mengadakan persisan yaitu sebuah prosesi mengelilingi Katedral dalam rangka mengenang Yesus memasuki Kota Yerusalem yang pada saat itu Beliau dianggap sebagai raja dengan sebutan "Hosana Filio David" (Emanuel da Santo, 2010: 33).

Rabu Trewa merupakan tradisi yang memili corak khas budaya Orang Nagi. Pada pagi harinya di kapela Tuan Ma dilaksanakan Mengaji Semana terakhir oleh suku Kapitan Jantera atau Fernandez Aikoli. Pada sore harinya Mama Muji mengaji untuk Tuan Mardomu Pintu Tuan Ma. Sesudah upacara Lamentasi Ratapan Nabi Yerimia yang bersamaan dengan selesainya Mama Muji mengaji, umat membuat bunyi-bunyian bising dengan memukul, menyeret, dan membanting seng, pipa besi, kayu, bambu hingga panci sambil berteriak "trewa, trewa, trewa!" sebagai tanda memasuki masa berkabung.

Kegiatan-kegiatan pada Kamis Putih didahului dengan perayaan Ekaristi oleh Uskup Larantuka yang bersifat liturgis. Sementara itu Tuan Mardomu bersama keluarganya, kerabat, dan umat melaksanakan tradisi tikam turo yaitu memasang tiang dari kayu kukung dan bambu untuk tempat pemasangan lilin untuk devosi prosesi Jumat Agung serta membangun ArmidaArmida. Sesudah perayaan Ekaristi di kapela Tuan Ma, Confreria melaksanakan upacara Muda Tuan yaitu 
membersihkan, memandikan, dan merias patung Tuan Ma di dalam kapela.

Subritual ini tertutup untuk umum.

Hanya Confreria dan orang-orang terpilih yang dapat ikut serta dalam Muda Tuan. Sebelum umat dan pesiarah dapat melakukan devosi Cium Tuan Ma, pintu kapela secara simbolis dibuka oleh raja. Pembukaan pintu Kapela Tuan Ma yang disebut dengan Buka Pintu Tuan ini adalah salah satu bagian dan permulaan subritual Cium Tuan Ma. Sebelum membuka pintu kapela, raja berdoa dan meminta izin dan restu kepada para leluhur dan raja-raja sebelumnya termasuk kepada Watowele. Setelah pintu Kapela di buka, dimulailah devosi Cium Tuan Ma.

Jumat Agung atau Sesta Vera adalah hari yang paling intens dalam hal berlangsungnya subritual di antara harihari lainnya dalam rangkaian ritual Semana Santa. Sekitar jam 18.00 waktu setempat dilaksanakan lamentasi di Katedral. Pelaksanaan Lamentasi diisi dengan menyanyikan lagu-lagu dengan tema duka atau ratapan agar suasana berkabung lebih intens. Sementara itu para Lakademu yang bertugas memikul patung Tuan Ana pada devosi pengarakan Jumat Agung memeriksa seluruh Armida yang akan menjadi tempat pemberhentian saat prosesi devosi tersebut. Saat nyanyian Popule Meus berlangsung, subritual pengarakan patung segera dimulai. Struktur urutan kelompok dalam subritual ini dari yang terdepan hingga belakang adalah Panji Confreria, Genda Do, para anak-anak yang membawa Ornamento sengsara, serikat Confreria, umat dan peisiarah, Penyanyi $O$ Vos dan Eus, biarawan dan biarawati, Imam pembawa Salib dan Misdinar, Patung Tuan Ana, para Promesa Tuan Ana, Patung Tuan Ma yang diiringi Presidenti Confreria dan Raja Larantuka, dan Promesa Tuan Ma.

\subsection{Dominasi Figur Bunda Maria Dalam Ritual Semana Santa}

Figur Bunda Maria memiliki implikasi yang masif pada masyarakat Larantuka. Hal ini tampak pada ideologi masyarakat lokal yang menjadikan Bunda Maria sebagai ratu pelindung Kota Larantuka. Figur suci yang menjadi panutan bagi para perempuan Larantuka khususnya ibu dalam menjalani kehidupannya. Indikasi dominasi figur Bunda Maria dapat ditemukan dalam ide, perilaku sosial yang dilakukan dengan sadar maupun tidak, dan artefak pada konstruksi sistem sosio-kultural masyrakat Larantuka. Hal tersebut lebih nampak pada ritual Semana Santa yang memang secara eksplisit diselenggarakan sebagai rasa hormat terhadap figur-Nya. Confreria atau Laskar Maria menjadi pihak penyelengara utama sekaligus pelestari ritual ini (Emanuel da Santo, 2010:33).

Menurut bernardus Tukan, perarakan ulang dalam penghayatan iman umat Katolik Larantuka bukan sekedar suatu upacara ritual belaka yang memperingati peristiwa yang telah terjadi dua ribu tahun yang lalu melainkan suatu kenangan akan peristiwa besar dalam kisah sengsara, wafat, kebangkitan Yesus, dan duka serta ketabahan Bunda Maria. Kenangan ini dirayakan selain dalam liturgi Ekaristi Kudus juga dalam subritual Jumat Agung. Nilai moral dan spiritual yang terkandung dalam peristiwa sengsara Yesus dan Bunda Maria mendorong masyarakat Larantuka mengambil bagian dalam sengsara tersebut yang merupakan refleksi dalam kenyataan penderitaan yang mereka alami dalam kehidupan sehari-hari sebagai mahkluk sosial yang terikat dalam sebuah sistem.

Selain makna Kristologis, devosi dan subritual Jumat Agung bermakna Mariologis. Bunda Maria bagi umat Larantuka diyakini sebagai sosok bunda 
yang menyaksikan secara langsung (saksi mata) peristiwa sengsara dan kebangkitan Putera-Nya. Bunda Maria yang disapa Tuan Ma ikut serta secara penuh dalam sengsara Putera-Nya. Keterkaitan antara makna Kristologis dan makna Marialogis ini membawa umat kepada suatu semangat menggereja yang sungguh terlibat dengan persoalan-persoalan yang dihadapi umat (Emanuel da Santo, 2010:46).

Semana Santa selalu memiliki tema pada setiap edisi tahunannya. Tema tersebut selalu berorientasi terhadap kesadaran penting atau patutnya mengenang duka dan ketabahan Bunda Maria. Menurut Tukan, apa yang dilakukan Bunda Maria dalam kisah sengsara dan penyaliban Yesus menjadi inspirasi bahkan pondasi ideologi masyarakat Larantuka dalam menanggapi dan menjalankan kehidupan dewasa ini. Terutama ide tentang ketabahan, kasih sayang, dan perjuangan tiada henti yang diimplementasikan dalam menjalani "kesengsaraan" kehidupan sosialekonomi.

Fenomena perubahan dalam budaya masyarakt Larantuka dari pra-Katolik menuju Katolik, wujud budaya yang berubah hanyalah pada tataran perilaku sosial dan artefak. Jika dilihat dengan teliti, nilai budaya masayarakat Larantuka mengenai penghormatan terhadap sosok perepuan atau seorang ibu tidak berubah. Nilai tersebut tetap eksis yang secara simbolik terepresentasi oleh figur Bunda Maria. Begitu kuat kebaktian masyarakat kepada Bunda Maria menyebabkan Raja Larantuka sendiri memberi gelar "Maria Reinha Larantuka".

Konsep ini lahir dari suatu pengalaman antropologis manusiawi bahwa seoarang Ibu memenuhi kebutuhan anaknya. Hubungan krusial tersebut lantas dikaitkan dengan hubungan anatara manusia denga alam.
Bumi dan alam raya beserta isinya (Mother Earth/Mother Nature) yang menyediakan kebutuhan-kebutuhan kehidupan manusia.

Etnis Lamoholot sebagai masayarakat awal Larantuka memiliki nilai budaya yang berbeda dengan masyarakat Larantuka dewasa ini yang sarat akan nilai budaya Katolik. Etnis Lamholot memiliki nilai budaya yang disebut Lewotana. Secara sederhana, Lewo atau Lewotana merupakan perkampungan tradisional. Namun bagi Orang Lamoholot, Lewotana tidak hanya merujuk pada suatu tempat hunian berupa kampung atau alam fisik belaka, Lewotana dipandang sebagai suatu kosmos atau jagad yang hidup. Suatu kosmos yang dipercaya memiliki jiwa atau roh. Sehingga apapun aktifitas yang mereka lakukan berorientasi terhadap nilai budaya tersebut. Termasuk aktifitas religius. Ide tentang suatu kosmos atau jagad yang hidup tersebut sejalan dengan sistem religi mereka yaitu Lera Wulan Tanah Ekan.

Lera Wulan, berarti "mataharibulan" lalu digabungkan menjadi satu kata yang berarti "langit". Sedangkan Tana Ekan berarti "bumi". Sistem kepercayaan mereka ini berangkat dari keyakinan dan kekaguman mereka akan adanya kekuatan yang dimiliki oleh alam atau kosmos. Alam semesta dilihat sebagai sesuatu yang sakral sehingga dianggap memiliki jiwa atau roh. Mereka juga percaya bahwa benda-benda alam seperti batu ataupun pohon-pohon besar sebagai tempat tinggal roh-roh para leluhur mereka.

Atas dasar nilai budaya Lewonata dan sistem religi Lera Wulan Tanah Ekan tersebut, Orang Lamaholot sangat menghormati lingkungannya. Alam raya dipandang sebagai sesuatu yang sakral yang telah memberikan mereka kehidupan juga sebagai tempat roh-roh atau jiwa leluhur mereka yang sudah meninggal dunia. Keberlangsungan dan 
kebutuhan hidup mereka, papan-pangansandang dan lainnya berasal dari alam sekitar. Menurut Yohanes Kelen, Orang Lamaholot memandang figur perempuan atau ibu tersebut adalah manifestasi dari alam raya. Sedangakan figur laki-laki adalah representasi seorang raja atau pemimpin yang harus memperlakukan alam sekitarnya dengan bijaksana. Hal tersebut lalu berkorelasi dalam kehidupan suami-istri. Istri sekaligus seorang ibu yang secara ideal senantiasa menjadi "sumber kehidupan" anak dan juga suaminya.

Etnis Lamaholot adalah masyarakat dengan orientasi berfikir yang feminis. Hal ini dapat ditegaskana dengan folklore dan mitologi mereka mengenai manusia pertama yaitu seorang perempuan bernama Watowele yang dikisahkan terlahir dari sebuah batu di Gunung Ile Mandiri. Ide tersebut merupakan bagian dari sistem religi etnis Lamaholot Lera Wulan Tanah Ekan. Kemudian diperkuat dengan adanya sosok supranatural yang bernama Tonu Wujo yang juga sesosok perempuan.

Tonu Wujo adalah sesosok dewi kesuburan, yang disakralkan; disembah dan diselenggarakan ritual baginya dalam kaitannya dengan sektor pertanian. Terutama setelah hadirnya patung jelmaan Tonu Wujo (yang sebenarnya adalah patung Tuan $M a$ ) di Larantuka. Menurut Bernardus Tukan, ikatan emosional dan psikologis antara orang Lamaholot dengan Tonu Wujo kuat dan intim. Eksistensi Tonu Wujo sangat krusial. Keadaan itu terus berlangsung hingga misionaris Portugis memperkenalkan Bunda Maria sekaligus menjelaskan bahwa patung jelmaan Tonu Wujo itu adalah patung Bunda Maria.

Masuknya unsur budaya Katolik yang memiliki figur atau sosok Perawan Suci Maria tidak mengalami banyak hambatan. Kisah hidup Bunda Maria yang menceritakan sifat-sifat mulia-Nya pun mendukung proses penerimaan ide baru bagi etnis Lamaholot. Ide baru yang membentuk "versi baru" Tonu Wujo. Terutama dengan adanya fenomena patung Tuan $M a$ yang sebelum kedatangan para misionaris dianggap oleh masyarakat pra-Katolik Larantuka adalah jelmaan sosok Tonu Wujo mempermudah budaya Katolik masuk mensubstitusi figur Tonu Wujo dengan Bunda Maria. Ditambah dengan citra Bunda Maria yang penuh dengan kasih sayang, ketabahan, dan penuh perjuangan, selaras dengan dengan nilai budaya Lamaholot yang sangat feminis.

\section{Simpulan}

Berdasarkan uraian yang telah dijelaskan pada Bab sebelumnya, maka pada bagian ini disampaikan beberapa simpulan.

1) Ritual Semana Santa diselenggarakan oleh masayarakat Larantuka yang dilatarbelakangi oleh emosi keagamaan khususnya umat Katolik Larantuka. Ritual ini secara kronologis memiliki memiliki sub-sub ritual pendukung tarhadap ritual utamanya. Ritual Semana Santa merupakan ritual yang diwariskan para misionaris Portugis dengan mengadopsi kearifan lokal budaya lokal. Ritual Semana Santa berlangsung mulai dari Minggu Palma, Rabu Trewa, Kamis Putih, Jumat Agung, Sabtu Santo, sampai dengan Minggu Alleluya (Paskah).

2) Latar belakang mengenai dominasi kultural figur Bunda Maria pada masyarakat Larantuka, khususnya dalam ritual Semana Santa berkaitan dengan nilai budaya etnis Lamaholot. Fenomena perubuhan sistem budayareligi masyarakat Larantuka dari Lera Wulan Tanah Ekan dan Lewotana menjadi budaya Katolik hanyalah berubah pada tataran perilaku sosial dan artefak atau fisik, ide mengenai nilai akan sakralnya sosok wanita 
yang dianggap sebagai representasi alam semesta tetap eksis dalam alam kognitif masyarakat Larantuka dengan figur Bunda Maria sebagai media proses subsitusi nilai feminis tersebut serta simbol sebagai "tempat" makna atas kekaguman dan penghormatan terhadap sosok wanita, khususnya ibu.

\section{Daftar Pustaka}

Emanuel da Santo, Fransiskus. 2010.

Hari Bae di Nagi Tana (Pekan suci di Larantuka). Larantuka. Komisi Kateketik Keuskupan Larantuka

Fernandez, Felix. 1997. Ziarah Imam Bersama: Ibu Maria Berduka Cita; Semana Santa di Larantuka-Nusa Tenggara Timur Indonesia. Jakarta. PT. Benza NOIA dan Yayasan Putera-Puteri Maria

Rudyansjah, Tony. 2015. Emile Durkheim: Pemikiran Utama dan Percabangannya ke RadcliffeBrown, Fortes, Levi-Strauss, Turner, dan Holbraad. Jakarta. Kompas

Sanderson, Stephen.K. 2011. Makrososiologi: Sebuah Pendekatan Terhadap Realitas Sosiologi. Jakarta. Rajawali Pers 